\title{
STRATEGI PENGEMBANGAN USAHA DAN PENINGKATAN KINERJA DALAM MENGHADAPI ERA DIGITAL PADA UMKM CAFÉ TIRTASARI KOTA PADANG
}

\author{
Emil Salim $^{1^{*}}$, Halifia Hendri ${ }^{2}$, Riska Robianto ${ }^{3}$ \\ ${ }^{1}$ Fakultas Ekonomi dan Bisnis, Universitas Putra Indonesia YPTK Padang, Indonesia \\ ${ }^{2,3}$ Fakultas IImu Komputer, Universitas Putra Indonesia YPTK Padang, Indonesia \\ emil_salim@upiyptk.ac.id, ${ }^{2}$ halifia_hendri@upiyptk.ac.id, ${ }^{3}$ riska_robianto@upiyptk.ac.id
}

\begin{abstract}
ABSTRAK
Abstrak: Pengabdian kepada masyarakat ini tujuan untuk mengembangkan usaha dan meningkatkan kinerja karyawan dalam menghadapi era digital saat ini. Strategi yang digunakan untuk mengembangkan usaha dan meningkatkan omzet pada era digital saat ini sangat berbeda dengan era-era sebelumnya. Pada era digital ini lebih banyak memanfaatkan media digital (online) baik itu dari segi promosi, layanan maupun penjualan. Strategi pengembangan usaha yang diberikan adalah dengan cara mendaftarkan Café tersebut ke aplikasi pengantar makanan online seperti Go-Food dan Grab-Food agar konsumen dapat berbelanja secara online. Selain itu, untuk metode promosi lebih baik menggunakan media sosial seperti Facebook (FB) dan Instagram (IG). Metode untuk peningkatan kinerja adalah dengan cara memberikan bonus kepada karayawan yang rajin dan disiplin. Berdasarkan pengamatan tingkat pemahaman mitra rata-rata sebesar 70\%. Hasil yang diperoleh oleh mitra setelah 3 bulan menerapkan metode ini adalah meningkatnya omzet penjualan sebesar 40\% dari sebelumnya.
\end{abstract}

Kata Kunci: Pengembangan usaha; Peningkatan kinerja; Era digital.

Abstract: Devotion to this community aims to develop business and improve the performance of employees in the face of the current digital era. The strategy used to grow the business and increase the turnover in the current digital period is very different from the previous ages. In this digital era, more utilizing digital media (online), both in terms of promotion, service, and sales. The business development strategy provided is to register the Café to an online food introduction application such as GoFood and Grab-Food so that consumers can shop online. Besides, for a better method of promotion using social media such as Facebook (FB) and Instagram (IG). The method for performance enhancement is to provide bonuses to diligent and disciplined employees. Based on the average partner's understanding rate of $70 \%$. The results obtained by the partner after three months of implementing this method is an increase in sales turnover of $40 \%$ than before.

Keywords: Business development; Performance improvement; Digital era.

\begin{tabular}{|c|c|c|}
\hline 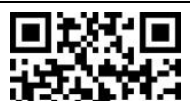 & $\begin{array}{l}\text { Article History: } \\
\text { Received: 30-11-2019 }\end{array}$ & (c) (†) (9) \\
\hline Pratip & $\begin{array}{l}\text { Revised : 03-02-2020 } \\
\text { Accepted: } 10-02-2020\end{array}$ & This is an open access article under the \\
\hline aptint & Online : $01-03-2020$ & $C C-B Y-S A$ license \\
\hline
\end{tabular}




\section{A. LATAR BELAKANG}

UMKM Café Tirtasari merupakan salah satu UMKM yang telah lama berdiri di Kota Padang sejak 8 tahun yang lalu.. Selama beroperasi UMKM ini berjalan dengan baik namun perkembangannya terkadang naik dan tekadang turun. Pada saat dilakukan wawancara dengan pemilik Café dia juga bingung dan tidak tahu apa penyebabnya, padahal lokasi Café tersebut berada di tempat keramaian dan strategis. Dari segi makanan yang dijual juga terasa enak dan beraneka ragam. Dari sagi tempat pelayanan sangat nyaman dan kondusif. Dengan dimikian maka penyebabnya harus dianalisis terlebih dahului.

Setelah dianalisis maka permasalahan yang dihadapi oleh mitra adalah kurangnya penggunaan teknologi saat ini. Pemillik hanya menggunakan cara lama dalam mengembangkan usaha dan meningkatkan kinerja. Ada baiknya pemilik memaanfaatkan aplikasi pengantar makanan online dan juga memanfaatkan media sosial yang banyak digunakan masyarakat pada umumnya, sehingga usaha tersebut akan berkembang dan kinerja akan meningkat (Wiandari \& Darma, 2017).

Manajemen sumber daya manusia merupakan suatu perencanaan, pengorganisasian, pengkoordinasian, pelaksanaan, dan pengawasan terhadap pengadaan, pengembangan, pemberian balas jasa, pengintegrasian, pemeliharaan, dan pemisahan tenaga kerja dalam rangka mencapai tujuan organisasi (Sadeli, 2018). Manajemen sumber daya manusia sebagai suatu pengelolaan dan pendayagunaan sumber daya yang ada pada individu (karyawan). Pengelolaan dan pendayagunaan tersebut dikembangkan secara maksimal di dalam dunia kerja untuk mencapai tujuan organisasi dan pengembangan individu karyawan (Mulyana, 2010), (Qustolani, 2017).

Pengembangan merupakan bagian yang tidak terpisahkan dari sistem ekonomi di masyarakat modern, khususnya di Indonesia. Pemasaran dengan menggunakan strategi promosi sudah berkembang menjadi sistem komunikasi yang sangat penting tidak saja bagi produsen barang maupun jasa tetapi juga bagi para konsumennya (Gurmilang, 2015). Kemampuan dan metode promosi dalam menyampaikan informasi kepada konsumen menjadikan hal tersebut sebagai hal yang penting dan berpengaruh terhadap keberhasilan pemasaran serta pembentukan suatu brand image bagi perusahaan (Ayuni, 2019). Pertumbuhan ekonomi dan mobilitas masyarakat kota Padang yang semakin meningkat, menyebabkan konsumsi barang dan jasa terus meningkat serta membuka peluang baru bagi masyarakat untuk membuka usaha guna untuk memenuhi kebutuhan akan permintaan juga untuk meningkatkan perekonomian masyarkat itu sendiri (Alam, Mitra, \& Magetan, 2018).

Sebagaimana diketahui bahwa produk ataupun jasa yang dihasilkan oleh perusahaan tidak mungkin dapat mencari sendiri pembeli atau peminatnya, oleh karena itu dibutuhkan aktivitas pengembangan yang 
mempunyai peranan sangat penting untuk keberhasilan atau kelangsungan untuk dapat bertumbuhkembang di pasarnya (Kurniawati, Santoso, \& Widowati, 2019). Disamping itu aktivitas pengembangan yang diterapkan harus ditinjau dan dikembangkan sesuai dengan perkembangan pasar dan lingkungan sekitar yang ada (Perusahaan \& Suseno, 2013), (Kusasih, Mutmainah, \& Dewi, 2018). Dengan demikian aktivitas pemasaran harus dapat memberikan gambaran yang jelas dan terarah tentang apa yang diberikan perusahaan dalam menggunakan setiap kesempatan atau peluang yang ada (Susanti, Nur Hidayati, \& Putri, 2018).

Perusahaan dapat menggunakan saluran langsung kepada konsumen untuk menjangkau dan mengirimkan barang dan jasa kepada pelanggan tanpa menggunakan perantara pemasaran. Pemasar langsung dapat menggunakan sejumlah saluran untuk menjangkau calon pelanggan perorangan, seperti surat langsung, pemasaran katalog, telemarketing, dan situs web. Perusahaan sering mencari respon terukur, umumnya pesanan pelanggan, melalui pemasaran pesanan langsung (Primanto \& Dharmmesta, 2019), (Bagus Nyoman Udayana \& Farida, 2019).

Disertai dengan berkembangnya teknologi yang semakin canggih, pemasaran bukan lagi sesuatu hal yang sulit untuk dilakukan. Teknologi telah mempermudah segala proses promosi dengan baik dan cepat dengan menggunakan beberapa media massa seperti, brosur, koran, majalah, maupun media lainnya seperti handphone, computer, faximile, dan lain-lain. Dengan beberapa media tersebut, strategi pemasaran melalui teknologi, ini dapat menunjang pertumbuhan penjualan secara efektif. Dengan database yang rinci, perusahaan mampu menghantarkan tawaran produk kepada konsumen dengan pembeli secara individu maupun berkelompok atau yang sering dikenal dengan istilah co-klient (Islami \& Nahartyo, 2019).

Beberapa badan usaha tidak berani dalam melakukan promosi yang akan membutuhkan modal yang lebih besar, meraka tidak menyadari bahwa dengan semakin bagusnya strategi promosi maka akan semakin baik pula terhadap volume penjualan (Setyawati \& Woelandari P.G, 2019). Kebanyakan dari badan usaha yang masih tergolong UMKM masih mempertahankan promosi secara manual atau hanya dari mulut ke mulut dan mengabaikan promosi lewat media sosial atau metode promosi lainnya yang akan membutuhkan biaya. Volume penjualan yang baik berawal dari strategi promosi yang baik. Konsumen hanya akan mengenal produk dan memutuskan untuk membeli produk melalui promosi yang baik (Weenas, 2013), (Roring, Oroh, \& Gulla, 2015).

Salah satu organisasi yang menyokong perekonomian adalah UMKM. UMKM Café Tiratasari merupakan salah satu UMKM yang baru berkembang yang telah berdiri selama 8 tahun. Dalam 8 tahun tersebut usaha itu mengalami pasang surut. Terkadang penjualan sangat tinggi terkadang rendah. Apa yang menyebabkan hal tersebut? Seharusnya usaha 
yang dilakukan bergerak semakin lama semakin meningkat. Saat dilakukan kunjungan ke lapangan ternyata terdapat banyak hal yang harus dibenahi seperti pemahaman pemilik mengenai strategi pemasaran dan peningkatan kinerja. Selain itu, juga harus memahami perkembangan era digital saat ini karena media digital sangat efektif untuk dimanfaatkan sebagai media promosi.

Berdasarkan fenomena ini maka tujuan pengabdian kepada masyarakat (PKM) ini adalah meningkatkan strategi pengembangan usaha dan peningkatan kinerja dalam menghadapi era digital pada UMKM Café Tirtasari sehingga berdampak pada peningkatan omzet yang diperolehnya.

\section{B. METODE PELAKSANAAN}

Kegiatan pengabdian ini dilaksanakan selama dua hari di Café Tirtasari oleh tiga orang tim Abdimas dari Universitas Putra Indonesia "YPTK" Padang, dengan jumlah anggota mitra yang terlibat sebanyak 10 orang meliputi pemilik dan karyawan Café serta peserta tambahan sebanyak 20 orang. Adapun tahapan-tahapan yang dilakukan oleh tim Abdimas guna menuntaskan permasalahan yang dihadapi oleh mitra sebagai berikut:

\section{Persiapan Kegiatan Pengabdian Pada Masyarakat}

Persiapan-persiapan yang dilakukan sebelum melaksanakan kegiatan pengabdian masyarakat sebagai berikut:

a. Pembentukan panitia pelaksana kegiatan Pengabdian Kepada Masyarakat (PKM) dan di SK-kan atau diberikan Surat Tugas oleh Ketua LPPM Universitas Putra Indonesia "YPTK" Padang.

b. Pembuatan proposal dan penyelesaian administrasi perizinan tempat atau lokasi pengabdian kepada masyarakat.

c. Mempersiapkan materi seminar dan menyebarkan undangan kepada Pemilik, Keryawan dan Pengunjung UMKM Café Tirtasari Kota Padang.

d. Survei ke lokasi kegiatan pengabdian kepada masyarakat oleh utusan dari panitia.

e. Mempersiapkan perlengkapan media seminar seperti (seminar kit, LCD proyektor, Sound Systems, Screen, dan peralatan lainnya).

\section{Pelaksanaan Kegiatan Pengabdian Kepada Masyarakat}

Dalam pelaksanaannya peserta akan terlibat aktif melalui forum seminar dan diakhiri dengan dialog-dialog untuk memunculkan pemahaman bersama. Berbagai materi dan permainan-permainan menjadi tawaran alternatif untuk peserta seminar dalam kegiatan belajar mengajar. Kegiatan seminar telah dikonsep dengan semenarik mungkin dan disesuaikan dengan materi pembelajaran secara umum. Adapun materi pelaksanaan kegiatan sesuai Tabel 1 berikut: 
14 | JMM (Jurnal Masyarakat Mandiri) | Vol. 4, No. 1, Maret 2020, hal. 10-17

Tabel 1. Daftar Pemateri dan Materi Seminar Hari ke-1

\begin{tabular}{lllr}
\hline \multicolumn{1}{c}{ Pemateri } & \multicolumn{1}{c}{ Materi Ajar } & \multicolumn{2}{c}{ Alat dan Bahan } \\
\hline Emil Salim & Strategi Pengembangan Usaha & Laptop, & LCD \\
\hline Halifia Hendri & Strategi Peningkatan Kinerja & Proyektor, & Sound \\
Riska Robianto & Era Teknologi dan Digital & Systems, & Screen, \\
& & Seminar Kid. & \\
\hline
\end{tabular}

\section{HASIL DAN PEMBAHASAN}

\section{Hasil Kegiatan Pengabdian Kepada Masyarakat}

Kegiatan pengabdian masyarakat ini memberikan hasil yang memuaskan karena dalam pelaksanaannya diberikan beberapa strategi pengembangan usaha dan peningkatan kinerja serta perkembangan teknologi di era digital saat ini.

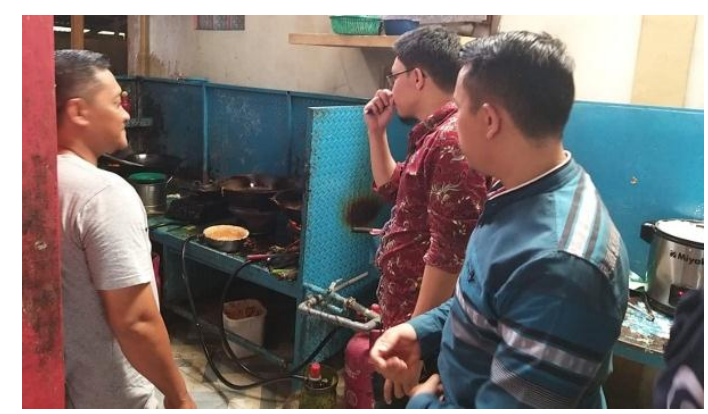

Gambar 1. Pemberian Pelatihan Pembenahan Ruang Memasak

Gambar 1 di atas merupakan proses pengecekan langsung ke ruang memasak UMKM Café Tirtasari. Pada ruangan memasak terdapat kompor memasak sebanyak 4 buah. Untuk meningkatkan jumlah produksi memasak lebih banyak maka kami sarankan untuk meningkatkan jumlah kompor menjadi 6 buah. Kegiatan ini juga berlangsung dengan baik, lancer dan efektif karena semangat dan antusias dari seluruh peserta dan pelaksana acara.

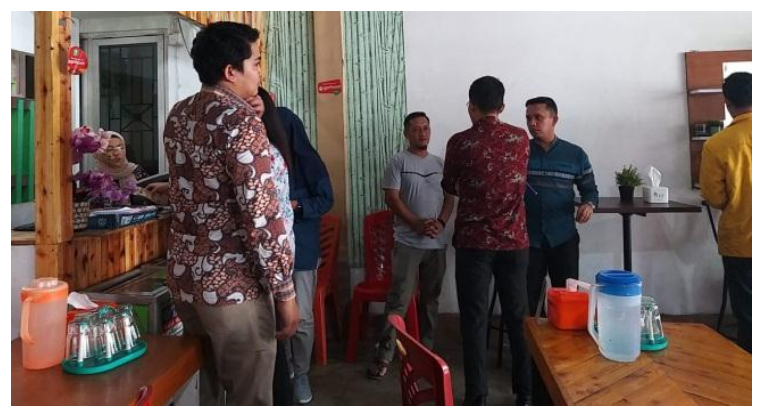

Gambar 2. Pemberian Pelatihan di Ruang Pelayanan Pelanggan

Gambar 2 di atas merupakan proses pemberian pelatihan di ruang pelayanan pelanggan UMKM Café Tirtasari. Pada ruangan pelayanan pelanggan terdapat meja dengan ukuran pengunjung yang bisa duduk sebanyak 2 orang. Untuk meningkatkan jumlah pelanggan yang bisa duduk lebih banyak maka kami sarankan untuk menyediakan ukuran 
meja dan kursi yang bervariasi seperti meja dengan ukuran 4 orang, 8 orang dan 10 orang. Selain dari itu juga disediakan kursi yang berjenis sofa dan panjang.

\section{Faktor Pendukung dan Penghambat Pengabdian Kepada Masyarakat}

Faktor-faktor yang mendukung terlaksananya kegiatan pengabdian kepada masyarakat ini adalah:

a. Tersedianya perlengkapan dan media untuk presentasi yang disediakan oleh Tim PKM membuat minat dan antusiasme peserta selama kegiatan sangat tinggi, hard copy untuk setiap peserta, video, musik dan robot serta berbagai pertanyaan dari peserta sehingga mereka dapat lebih memahami apa yang diberikan dan dijelaskan selama kegiatan berlangsung.

b. Sarana dan prasarana yang dibutuhkan seperti tempat yang bersih, nyaman dan sejuk sehingga sangat kondusif untuk dilaksanaknnya seminar.

c. Hadiah diberikan kepada peserta untuk apresiasinya dalam diskusi.

d. Dukungan penuh dari peserta yang memberikan fasilitas tempat dan sarana prasarana lainnya sehingga suksesnya kegiatan tersebut.

Faktor-faktor yang menghambat terlaksananya kegiatan pengabdian kepada masyarakat ini adalah:

a. Keterbatasan waktu dalam pelaksanaan kegiatan tersebut.

b. Kefokusan seluruh peserta terhadap materi yang dijelaskan karena peserta seminar rata-rata masih berusia muda.

\section{SIMPULAN DAN SARAN}

Berdasarkan hasil pelaksanaan kegiatan ini diperoleh informasi bahwa bertambahnya pengetahuan pemilik, karyawan dan pengunjung UMKM Café Tirta Sari tentang strategi pengembangan usaha sebesar $60 \%$ dan juga tentang strategi peningkatan kinerja karyawan sebesar $70 \%$ serta tentang teknologi dan era digital sebesar $80 \%$. Selain itu, meningkatnya omzet penjualan sebesar $40 \%$ dari pada sebelumnya. Sehingga tim Abdimas menyarankan perlu ditingkatkannya fasilitas kenyamanan dan hiburan bagi pengunjung UMKM Café Tiratasari seperti kipas angin, pendingin udara (AC), televisi LED ukuran besar, speaker aktif dan Audio Visual lainnya agar pengunjung betah berlama-lama dan sering-sering mengunjungi Café.

\section{UCAPAN TERIMA KASIH}

Tim penulis mengucapkan terima kasih kepada Lembaga Penelitian dan Pengabdian Masyarakat (LPPM) Universitas Putra Indonesia YPTK Padang yang telah memberikan Surat Tugas dan semua perizinan dalam 
melaksanakan kegiatan Pengabdian Kepada Masyarakat ini. Terkhusus terimakasih banyak kepada pemilik UMKM Cafe Tirtasari yang telah mengizinkan tempat miliknya sebagai lokasi kegiatan ini.

\section{DAFTAR RUJUKAN}

Alam, P. T., Mitra, D., \& Magetan, R. (2018). Analisis Pengaruh Karakteristik Individu Dan Karakteristik Organisasi Terhadap Pengembangan Karier Pegawai Pada Pt. Alam Damai Mitra Raya Magetan. Jurnal Manajemen Sumber Daya Manusia, 12(2), 148-158.

Ayuni, R. F. (2019). the Online Shopping Habits and E-Loyalty of Gen Z As Natives in the Digital Era. Journal of Indonesian Economy and Business, 34(2), 168. https://doi.org/10.22146/jieb.39848

Bagus Nyoman Udayana, I., \& Farida, N. (2019). the Factors Which Influence the Relationship Between a Network'S Synergizing Capability and the Increase in a Salesperson'S Performance. Journal of Indonesian Economy and Business, 34(2), 131. https://doi.org/10.22146/jieb.29221

Gurmilang, A. (2015). Komunikasi Pemasaran Sebagai Metode Promosi untuk Usaha Kecil Menengah. Widyakala Journal, 2(1), 126. https://doi.org/10.36262/widyakala.v2i1.16

Islami, I. N., \& Nahartyo, E. (2019). Do Leadership Styles Moderate the Relationship of Organizational Commitment and Budgetary Slack? an Experimental Approach. Journal of Indonesian Economy and Business, 34(2), 150. https://doi.org/10.22146/jieb.32285

Kurniawati, E., Santoso, A., \& Widowati, S. Y. (2019). Penyuluhan Arti Pentingnya Merk Dagang. JMM (Jurnal Masyarakat Mandiri), 2(1), 66. https://doi.org/10.31764/jmm.v2i1.1350

Kusasih, Mutmainah, \& Dewi. (2018). Analisis Kualitas Dan Persepsi Nilai Terhadap Kepuasan Pelanggan. Jurnal Manajemen Sumber Daya Manusia, $12,159-168$.

Mulyana, M. (2010). Manajemen sumber daya manusia (sdm) ritel dalam meningkatkan kinerja perusahaan. Jurnal Ilmiah Ranggagading, Volume 10(October 2010), 164-170 MANAJEMEN.

Perusahaan, L., \& Suseno, Y. D. (2013). 3) 1, 2, 3). 169-183.

Primanto, A. B., \& Dharmmesta, B. S. (2019). What Happens After They Laugh: How Humorous Advertisements Have an Effect on Consumers' Attitudes, Word of Mouth Intentions, and Purchase Intentions, With the Need for Humor Playing a Moderating Role. Journal of Indonesian Economy and Business, 34(2), 117. https://doi.org/10.22146/jieb.23036

Qustolani, A. (2017). Pengaruh Kepuasan Kerja, Keadilan Prosedural Dan Kompensasi Terhadap Kinerja Karyawan. Jurnal Ilmiah Manajemen \& Akuntansi, 4(2), 78-86.

Roring, F., Oroh, S., \& Gulla, R. (2015). Analisis Harga, Promosi, Dan Kualitas Pelayanan Terhadap Kepuasan Konsumen Pada Hotel Manado Grace Inn. Jurnal Riset Ekonomi, Manajemen, Bisnis Dan Akuntansi, 3(1), 1313-1322.

Sadeli, A. H. (2018). Manajemen Usaha Home Industry Desa Sindangsari Kecamatan Sukasari Kabupaten Sumedang. Dharmakarya, 71). https://doi.org/10.24198/dharmakarya.v7i1.11866

Setyawati, N. W., \& Woelandari P.G, D. S. (2019). Pemberdayaan Masyarakat Melalui Pendampingan Program Kerja Berbasis Manajemen Lingkungan. $\begin{array}{lllll}\text { JMM (Jurnal } & \text { Masyarakat }\end{array}$ https://doi.org/10.31764/jmm.v0i0.1080

Susanti, V. D., Nur Hidayati, S. Q., \& Putri, A. N. (2018). Pelatihan "Basho Kanel" Baby Shoes Kain Flanel Sebagai Bekal Wirausaha Mandiri Bagi Remaja Putri 
Panti Asuhan Siti Hajar Madiun. JMM (Jurnal Masyarakat Mandiri), 203. https://doi.org/10.31764/jmm.v0i0.1428

Weenas, J. (2013). Kualitas Produk, Harga, Promosi Dan Kualitas Pelayanan Pengaruhnya Terhadap Keputusan Pembelian Spring Bed Comforta. Jurnal Riset Ekonomi, Manajemen, Bisnis Dan Akuntansi, 1(4), 607-618.

Wiandari, I. A. A., \& Darma, G. S. (2017). Kepemimpinan, Total Quality Management, Perilaku Produktif Karyawan, Kinerja Karyawan dan Kinerja Perusahaan. Jurnal Manajemen Bisnis, 14(2), 61-78. 